\title{
One-fourth of the prisoners are underweight in Northern Ethiopia: a cross- sectional study
}

Semaw Ferede Abera ${ }^{1,2^{*}}$ and Kelemework Adane ${ }^{3}$

\begin{abstract}
Background: Despite the fact that prisoners are exposed to different health problems, prison health problems are often overlooked by researchers and no previous study has investigated nutritional problems of prisoners in Ethiopia.

Methods: Cross-sectional data were collected from 809 prisoners from nine major prison setups in the Tigray region of Ethiopia. A proportional stratified sampling technique was used to select the total number of participants needed from each prison site. The outcome of this study was underweight defined as body mass index (BMI) of less than $18.5 \mathrm{~kg} / \mathrm{m}^{2}$. Multivariable binary logistic regression was performed to identify determinants of underweight at a $p$-value of less than 0.05 .
\end{abstract}

Results: The prevalence of underweight was $25.2 \%(95 \% \mathrm{Cl} ; 22.3 \%-28.3 \%)$. Khat Chewing $(\mathrm{OR}=2.08 ; 95 \% \mathrm{Cl}=1.17,3.70)$ and longer duration of incarceration $(\mathrm{OR}=1.07 ; 95 \% \mathrm{Cl}=1.01,1.14)$ were associated with a significantly increased risk of underweight. Additionally, previous incarceration $(\mathrm{OR}=1.54 ; 95 \% \mathrm{Cl}=0.99,2.42)$ was a relevant determinant of underweight with a borderline significance. In contrast, family support $(\mathrm{OR}=0.61 ; 95 \% \mathrm{Cl}=0.43,0.85)$ and farmer occupation $(\mathrm{OR}=0.59 ; 95 \% \mathrm{Cl}=0.36,0.98)$ compared to those who were unemployed were important protective determinants significantly associated with lower risk of underweight.

Conclusion: In summary, the burden of underweight was higher among prisoners in Tigray region who had respiratory tract infections. The study has enhanced our understanding of the determinants of underweight in the prison population. We strongly recommend that nutritional support, such as therapeutic feeding programs for severely or moderately underweight prisoners, and environmental health interventions of the prison setups should be urgently implemented to correct the uncovered nutritional problem and its associated factors for improving the health status of prisoners.

\section{Background}

Prisoners are exposed to a number of unfavorable health and health deterring factors including higher risks of mortality and injuries [1-5]. A remarkable feature of prisoners is that they often arrive at health service centers with a number of health and social problems which can lead to a high risk of malnutrition [6-8].

The literature indicates that prisoners face different nutritional problems ranging from several micronutrient

\footnotetext{
* Correspondence: semawfer@yahoo.com

'School of Public Health, College of Health Sciences, Mekelle University, Mekelle, Ethiopia

${ }^{2}$ Kilte Awlaelo- Health and Demographic Surveillance Site, Mekelle University, Tigray, Ethiopia

Full list of author information is available at the end of the article
}

deficiencies, re-emerging severe diet related diseases to delayed recovery, mental illness, sexual health problems, infectious diseases, a wide range of risk factors and increased risk of mortality [6, 7, 9-20].

Studies reported that poor nutrition was significantly associated with severity of pneumococcal pneumonia and risk of acquiring tuberculosis infection [21, 22]. Several other studies showed that underweight and micronutrient deficiencies were associated with higher odds of respiratory infections [23-25].

In general, in Africa, there is limited evidence on the various health problems of prisoners despite the relevance of such evidence on the health of the prisoners, their inmates, and the general community. In the case of Ethiopia, the prison health system seems to be not well integrated 
with the national health system and health problems of prisoners are mostly marginalized by researchers.

According to the 2015 report by World Prison Brief (WPB) and Institute for Criminal Policy Research (ICPR), in Ethiopia, the total prison population has grown by $66.9 \%$ since 2000, reaching 104,467 in 2010/2011 [26]. One of the basic human rights that prisoners, according to the Universal Declaration of Human Rights (UDHR) Article 25 (1), must have is access to adequate and healthy food choices [27] to meet their nutritional needs. Additionally, Mandela rule 22 states that "Every prisoner shall be provided by the prison administration at the usual hours with food of nutritional value adequate for health and strength, of wholesome quality and well prepared and served. Drinking water shall be available to every prisoner whenever he or she needs it." [28].

To the authors' best knowledge, the prevalence and associated factors of underweight has been scarcely researched from the perspective of prison settings. Therefore, this paper determines the prevalence and determinants of underweight among adult prisoners who had respiratory tract infections from 6 zonal and 3 district prison institutions located in Tigray region, northern Ethiopia.

\section{Methods}

\section{Study area, setting and period}

This study was implemented in Tigray region in northern Ethiopia as part of the tuberculosis (TB) study in prisons [29]. In the study, it was reported that the prevalence of culture confirmed TB was $4 \%$ (95\% CI: 2.65-5.35).

In the regional state, there are nine major zonal and district prison institutions. During our study, there were 2557 prisoners in Mekelle prison site, 1513 in Shire, 1093 in Adigrat, 634 in Wukro, 653 in Axum, 537 in Adwa, 786 in Maichew, 710 in Alamata, and 875 in Humera. A quantitative cross sectional study design was conducted in all these nine prison sites with a source population of 9326 prisoners from August 2013 to February 2014.

\section{Inclusion and exclusion criteria}

The inclusion criteria of our study were cough lasting for more than two weeks and fulfillment of at least one suggestive symptom of TB (such as night sweating, chest pain and/ or weight loss) among prisoners aged 18 years and above. Prisoners who fulfilled the inclusion criteria but were assessed to be mentally ill were excluded from the study.

\section{Source population, sample size calculation and sampling method}

Of the total 9, 326 adult prisoners in the regional state, data were collected from 809 participants. Assuming a $50 \%$ prevalence of underweight, $5 \%$ precision, a design effect of 2, 95\% confidence level and a 5\% non-response rate, we calculated a sample size of 809 adult prisoners using a single proportion formula.

$$
\mathrm{n}=\frac{\mathrm{z}^{2} \mathrm{p}(1-\mathrm{p})}{\mathrm{d}^{2}}=\frac{(1.96)^{2}(0.5)(1-05)}{(0.05)^{2}}=384.2 \approx 385
$$

Accounting for the design effect of 2 and 5\% expected response rate, the final sample size was 809 . $\mathrm{n}_{\text {final }}=(385 \times 2)=770+5 \%$ non-response rate $=770+39=809$ participants. Then, we multiplied the total prisoners in each of the nine prison sites by the strata-specific coefficient, 0.2432 , to obtain the total number of prisoners from each prison site. Through room to room visits, with the guidance of the prison nurses in each site, data collectors asked if there were prisoners who suffered from coughing lasting two weeks or more. Next, we used a convenient sampling technique to select the eligible participants, who fulfilled the set inclusion criteria, from the total prisoners in each prison site. Finally, information about the objective and relevance of the study including detail guidance on informed consent was provided according to our study guidelines. Accordingly, selected participants in our study ranged from 46 in Adwa prison site to 222 in Mekelle prison site.

\section{Data collection and management}

Experienced nurses and clinical officers screened the potential participants based on the inclusion criteria we set. Aiming to minimize inter-observer variation amongst our data collectors, training was given to the data collectors before they collected data using the structured questionnaire. Collected data from the questionnaire were double checked for completeness both by supervisors and data collectors. Accordingly, incomplete and implausible values were corrected on the spot.

\section{Outcome variable}

The outcome of interest was underweight as measured using the body mass index (BMI), defined as the weight in kilograms divided by the square of the height in metres $\left(\mathrm{kg} / \mathrm{m}^{2}\right)$. The body weight was determined to the nearest $0.1 \mathrm{~kg}$ on a standing electronic digital scale and height was measured to the nearest 0.1 centimeter $(\mathrm{cm})$. BMI was calculated for each participant and their nutritional status was categorized according to World Health Organization (WHO) standards [30, 31]. Accordingly, a participant was declared to be underweight if the BMI metrics is less than $18.5 \mathrm{~kg} / \mathrm{m}^{2}$.

\section{Explanatory variables}

Data on socio-demographic characteristics (age, sex, residence, marital status, education and occupation), family support, prison site, condition of the prisoners (whether 
the sentenced was or not), lifestyle profile during the study period (smoking, khat chewing) and before imprisonment (alcohol consumption, khat chewing) were collected. In addition, Human Immunodeficiency Virus (HIV) serological status, TB status, duration of cough, history and frequency of previous imprisonment and duration of current imprisonment were also obtained. HIV $(1+2)$ Antibody Colloidal Gold (KHB) and Stat-Pak were used to initially test our samples and confirm the positive ones respectively. HIV-1/2 Unigold Recombinant assay was applied as a gold standard tie breaker for discordant HIV test results. Individual based pre-test and post-test HIV Counseling and Testing (HCT) was implemented confidentially according to the national guideline for HCT recommended by the Federal Ministry of Health (FMoH) of Ethiopia. Our diagnosis for pulmonary tuberculosis (PTB) was based on three consecutive early morning sputum samples. A bacteriologically confirmed positive PTB status was defined as a positive culture for M.tuberculosis and/or two smear positive sputum samples for the presumptive TB cases under a direct microscopy. Moreover, family support was operationally defined as family visit plus food aid or family visit plus money support or a combination of family visit, food aid and money support. Data on all other explanatory variables were taken from observation, such as sex of participants or from the response of the participants to each question during the interview.

\section{Statistical methods}

The data was entered using Epi Data entry version 3.1 software. The raw dataset was exported to stata 13.0 for cleaning and data analysis. Frequency analysis was run to explore the range of values, identify missing data or possibly miscoded data. Then, a deep cautious exploratory data analysis was performed for the distribution of each continuous variable to prepare it for final analysis. Age and frequency of current imprisonment were not normally distributed and median and Interquartile range was used to summarize these variables.

Univariate association between each individual explanatory variable and underweight was evaluated using odds ratio (OR) with the corresponding 95\% confidence interval $(\mathrm{CI})$ as a parameter estimate. The next step was to build a statistical model, excluding the 22 overweight or obese cases, which identified the determinants of underweight among the adult prisoners. To build this model, all the predictor variables with a $p$-value of $<0.05$ on the bivariate analysis were fitted.

Accordingly, this model was built using age, family support, current smoking, current khat chewing and history of previous incarceration. In the next step, we purposely included additional explanatory variables which were statistically significant a $p$-value of $<0.25$ to build an empirical model [32]. In our analysis, a potential problem of multicollinearity was checked using variance inflation factor (VIF) at cut off point of 10 [33]. Interaction was also checked and we found no significant interaction terms. Finally, in the multivariable binary logistic model, a $p$-value of $<0.05$ was considered to declare statistical significance with the corresponding 95\% confidence interval. The goodness of fit (GOF) of our model was checked using Hosmer-Lemeshow GOF test. The $p$-value of the Hosmer-Lemeshow GOF test of our model is 0.427 which confirms that the model is correctly specified.

\section{Results}

\section{Overall situation of the prison setups}

The largest prison institution in Tigray regional state is Mekelle prison, located in the state capital. During our observation, most prisons had very narrow windows while others had no windows at all. According to prison authority officials, the main reason of this was the fear that prisoners could escape. We also found that most prisoners had clinics which were poorly equipped, mostly with basic emergency level medical supplies, staffed by diploma holding nurses who were formerly assistant military nurses. There were no physicians or health professionals holding a Bachelor's degree in any of the clinics. All the nurses reported that they did not participate in any formal training either by the regional health system or non-governmental organization.

From the perspective of the prisoners, in all the prison setups, prisoners complained of poor referral systems, bad environmental sanitation such as unsanitary toilets, problems of insomnia due to overcrowding and pests like fleas. Most study participants reported different dermatological problems such as itching. Additionally, 770 (95.2\%), participants slept on the floor using a mattress mostly filled with grass or solely on carpet.

\section{Nutritional status of prisoners by socio-demographic characteristics}

The response rate was $100 \%$. The prevalence of underweight among prisoners with respiratory tract infection was $25.2 \%$ (95\% CI: $22.3 \%-28.3 \%$ ). The burden of underweight varies substantially from prison to prison, ranging from a minimum prevalence of $12.9 \%$ in Alamata prison site to a maximum of $53.7 \%$ in Adigrat prison site. Next to Adigrat, prisoners from Axum, Humera and Maichew prison sites had greater prevalence of underweight (Fig. 1). In our study, 29 (3.6\%), 44 (5.4\%) and131 (16.2\%) of the prisoners were severely, moderately and mildly underweight respectively.

More than three-fifths, 124 (60.8\%), of the underweight burden was among the age group 18-30. The mean age of those who were underweight was lower than those who were not underweight (Table 1). 


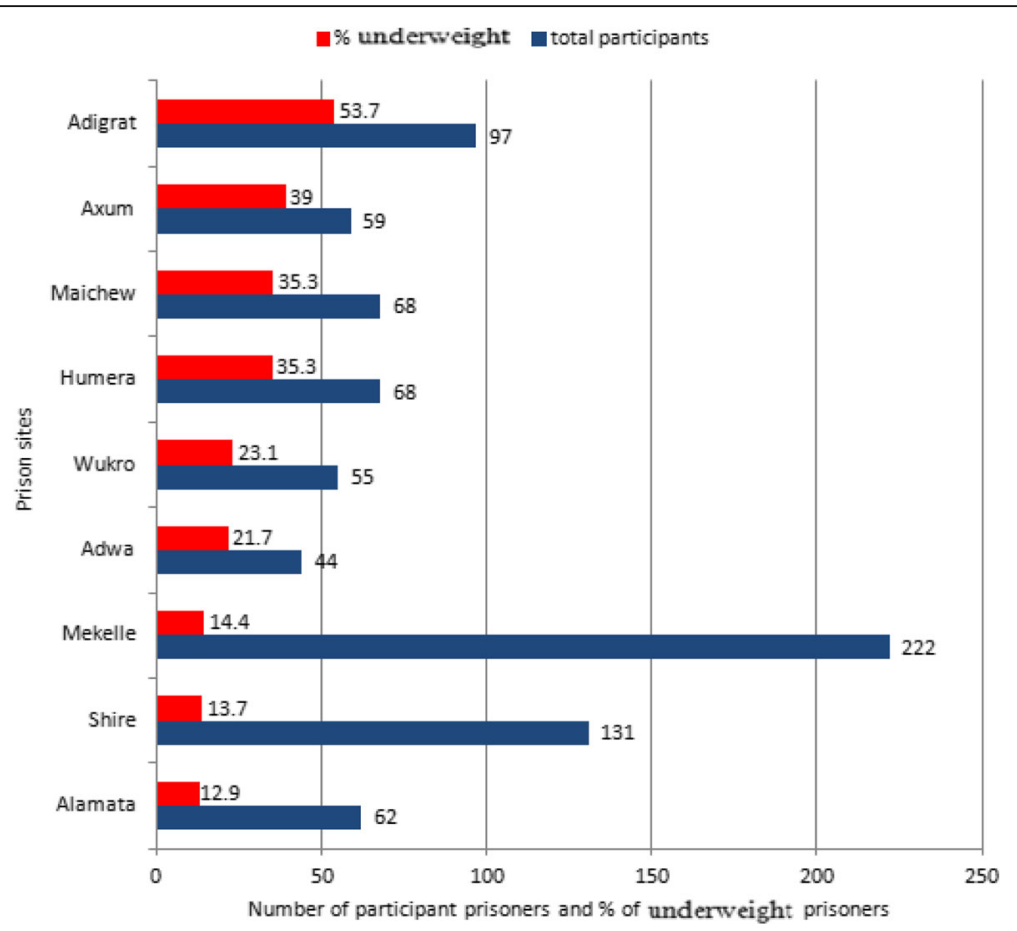

Fig. 1 Total number of prisoners who participated in the study with the corresponding proportion of underweight prisoners by prison site in Tigray region, Ethiopia

The prevalence of underweight was higher among prisoners who were not getting family support (30.6\%), single by marital status $(29.4 \%)$, and among people who had primary $(27 \%)$ or secondary (28.8\%) education. Moreover, those who were students (36\%) and unemployed (33.3\%) had also higher burden of underweight (Table 1).

\section{Nutritional status of prisoners by lifestyle, morbidity and other prison related conditions}

The mean duration of incarceration was 29.7 months. Stratified by our outcome of interest, this was 28.8 months for those who were not underweight and 32.4 months for those who were underweight; this difference was statistically significant $(p<0.001)$. There was a $9.5 \%$ excess prevalence of underweight among prisoners who were smoking compared to those prisoners who were not smokers. Nearly half, 34 (44.7\%), of those who chew khat were underweight compared to about one-fourth of those who did not chew khat. Furthermore, the prevalence of underweight was lower by $4 \%$ among prisoners who were imprisoned for less than 12 months compared to the prisoners who were incarcerated for longer than 12 months (Table 2).

On the other hand, the prevalence of underweight was higher among prisoners who were imprisoned previously (12.7\% excess prevalence), HIV positive (8.5\% excess prevalence), and for those with culture confirmed PTB cases $(12.8 \%$ excess prevalence) (Table 2$)$. We also observed that the mean age of participants with a history of incarceration (25.4 years) was lower than the mean age of those who did not have a history of incarceration (30.3 years), but this difference was not statistically significant $(p=0.073)$.

\section{Factors associated with underweight among prisoners with respiratory infections}

Adjusted for the fitted covariates shown in Table 3, prisoners who were supported by their families had a 39\% $(\mathrm{OR}=0.61 ; 95 \% \mathrm{CI}=0.43,0.85)$ lower odds of underweight compared to those prisoners who were not getting family support. Another remarkable finding was that prisoners who reported chewing khat were two times $(\mathrm{OR}=2.08$; $95 \% \mathrm{CI}=1.17,3.70)$ more likely to be underweight compared to those who did not chew khat (Table 3).

Moreover, compared to prisoners who were unemployed before being jailed, prisoners who were farmers had a $41 \%$ $(\mathrm{OR}=0.59 ; 95 \% \mathrm{CI}=0.36,0.98)$ lower risk of becoming underweight. For every 1 year additional incarceration in the prison setups, the odds of underweight increases by $7 \%$ $(\mathrm{OR}=1.07 ; 95 \% \mathrm{CI}=1.01,1.14)$. Additionally, those prisoners with a history of previous incarceration had a $54 \%$ excess risk, $(\mathrm{OR}=1.54 ; 95 \% \mathrm{CI}=0.99,2.42)$, of getting underweight compared to those who were jailed for their first time (Table 3).

Prisoners who had HIV $(\mathrm{OR}=1.50 ; 95 \% \mathrm{CI}=0.70,3.21)$ and $\mathrm{TB}(\mathrm{OR}=1.44 ; 95 \% \mathrm{CI}=0.66,3.12)$ had $50 \%$ and $44 \%$ 
Table 1 Nutritional status of prisoners by socio-demographic characteristics of adult prisoners in Tigray region, northern Ethiopia $(n=809)$

\begin{tabular}{|c|c|c|c|c|}
\hline \multirow[t]{2}{*}{ Variables } & \multicolumn{2}{|l|}{ Nutritional status } & \multirow{2}{*}{$\begin{array}{l}\text { Total } \\
(N=809)\end{array}$} & \multirow[t]{2}{*}{$p$-value } \\
\hline & $\begin{array}{l}\text { Not underweight, } \\
n(\%) ;(n=605)\end{array}$ & $\begin{array}{l}\text { Underweight, } \\
n(\%) ;(n=204)\end{array}$ & & \\
\hline Age (median \pm IQR) & $30 \pm 16$ & $27 \pm 16$ & $29 \pm 16$ & \\
\hline Sex & & & & 0.880 \\
\hline Female & $16(76.2)$ & $5(23.8)$ & 21 & \\
\hline Male & $589(74.8)$ & 199 (25.3) & 788 & \\
\hline Residence & & & & 0.600 \\
\hline Rural & $339(75.5)$ & $110(24.5)$ & 449 & \\
\hline Urban & $266(73.9)$ & $94(26.1)$ & 360 & \\
\hline Family support & & & & $0.001^{*}$ \\
\hline No & $270(64.4)$ & 119 (30.6) & 389 & \\
\hline Yes & $335(79.8)$ & $85(20.2)$ & 420 & \\
\hline Marital status & & & & 0.056 \\
\hline Married & $320(77.7)$ & $92(22.3)$ & 412 & \\
\hline Single & $245(70.6)$ & $102(29.4)$ & 347 & \\
\hline Divorced/ widowed & $40(80)$ & $10(20)$ & 50 & \\
\hline Educational status & & & & 0.063 \\
\hline No formal education & $161(77.4)$ & $47(22.6)$ & 208 & \\
\hline Primary & $290(73)$ & $107(27)$ & 397 & \\
\hline Secondary & $109(71.2)$ & $44(28.8)$ & 153 & \\
\hline College and above & $45(88.2)$ & $6(11.8)$ & 51 & \\
\hline Occupation & & & & $0.003^{*}$ \\
\hline Unemployed & $86(66.7)$ & $43(33.3)$ & 129 & \\
\hline Civil servant & $72(78.3)$ & $20(21.7)$ & 92 & \\
\hline Farmer & $316(79.6)$ & $81(20.4)$ & 397 & \\
\hline Student & $64(64)$ & $36(36)$ & 100 & \\
\hline Others occupation & $67(73.6)$ & $24(26.4)$ & 91 & \\
\hline
\end{tabular}

*indicates $p$-value $<0.05$ from the chi-square test analysis; IQR Inter Quartile Range

higher odds of being underweight, respectively. However, these differences were statistically insignificant (Table 3).

Figure 2 shows the independent effect of each fitted variable represented by forest plots. The dot in each plot represents the estimate of the adjusted odds ratio and the width of each plot shows the 95\% confidence interval of the corresponding adjusted odds ratio (Fig. 2).

\section{Discussion}

In general, this study demonstrates that underweight affects one in every four of our sample population. Khat chewing, prolonged duration of incarceration and unemployment were significant determinants of underweight in the incarcerated population. Previous history of incarceration was also an important determinant with a borderline significance. Moreover, family support was a significant protective determinant of underweight among the prisoners.
One of the main goals of this study was to determine the burden of underweight among adult prisoners who had respiratory tract infections. We found that $25.2 \%$ of the adult prisoners were underweight, of which $35.8 \%$ were either severely or moderately underweight, which suggests that underweight is a significant public health problem among prisoners in Tigray region.

The high prevalence of underweight observed among the prisoners could be partly influenced by many factors. One of the important justifications comes from the clinical fact that respiratory infection by itself could lead to malnutrition [34] by mechanisms such as weight loss due to increased basal metabolic rate, poor appetite and metabolic losses of nutrients. However, malnutrition could also be a risk factor for increased risk of infections [35-37] and may be an important indicator of prognosis from infectious diseases of the respiratory system [38, 39]. Additionally, multiple other studies have also demonstrated that prisoners were suffering 
Table 2 Lifestyle, morbidity and other prison related condition of adult prisoners in Tigray region, northern Ethiopia $(n=809)$

\begin{tabular}{|c|c|c|c|c|}
\hline \multirow[t]{2}{*}{ Variables } & \multicolumn{2}{|l|}{ Nutritional status } & \multirow{2}{*}{$\begin{array}{l}\text { Total } \\
(N=809)\end{array}$} & \multirow[t]{2}{*}{$p$-value* } \\
\hline & $\begin{array}{l}\text { Not underweight, } \\
n(\%) ;(n=605)\end{array}$ & $\begin{array}{l}\text { Underweight, } \\
n(\%) ;(n=204)\end{array}$ & & \\
\hline Smoking status & & & & $0.011^{*}$ \\
\hline No & $490(76.8)$ & $148(23.2)$ & 638 & \\
\hline Yes & $115(67.3)$ & $56(32.7)$ & 171 & \\
\hline Chew khat & & & & $<0.001^{*}$ \\
\hline No & $563(76.8)$ & $170(23.2)$ & 733 & \\
\hline Yes & $42(55.3)$ & $34(44.7)$ & 76 & \\
\hline Alcohol use before jail & & & & 0.626 \\
\hline No & $359(74.2)$ & $125(25.8)$ & 484 & \\
\hline Yes & $246(75.7)$ & 79 (24.3) & 325 & \\
\hline Duration of jail & & & & 0.203 \\
\hline$<12$ months & $250(77.2)$ & $74(22.8)$ & 324 & \\
\hline$\geq 12$ months & $355(73.2)$ & $130(26.8)$ & 485 & \\
\hline HIV serostatus & & & & 0.251 \\
\hline Negative & $581(75.2)$ & $192(24.8)$ & 773 & \\
\hline Positive & $24(66.7)$ & $12(33.3)$ & 36 & \\
\hline Tuberculosis & & & & 0.103 \\
\hline No & $585(75.3)$ & $192(24.7)$ & 777 & \\
\hline Yes & $20(62.5)$ & $12(37.5)$ & 32 & \\
\hline Previous jail history & & & & $0.004^{*}$ \\
\hline No & $520(76.1)$ & $163(23.9)$ & 683 & \\
\hline Yes & $71(63.4)$ & $41(36.6)$ & 112 & \\
\hline Cough duration & & & & 0.690 \\
\hline 2-4 weeks & $216(74)$ & $76(26)$ & 292 & \\
\hline$\geq 4$ weeks & $389(75.2)$ & $128(24.8)$ & 517 & \\
\hline
\end{tabular}

* indicates $p$-value $<0.05$ from the chi-square test analysis

from several micronutrient deficiencies that could predispose them to severe forms of infections in addition to other health problems such as depression and mortality [9-11, 14, 19, 40-44]. In our study, 9\% of the prisoners were either severely or moderately underweight. Hence, implementing therapeutic feeding program for such prisoners and general food distributions for the mildly underweight and normal prisoners could lead a sharp decline of underweight rates [45] and contribute to prevention of epidemics in such vulnerable population. Since our study was implemented using cross-sectional design, as part of our study's shortcoming, we are unable to demonstrate whether the respiratory infections had caused underweight or the reverse. However, the study indicates that nutritional needs of prisoners should be optimized to ensure adequate nutritional status of prisoners.

Moreover, morbidity from respiratory infections of at least two weeks could also be associated with poor access to appropriate health care service, as reported in several studies [46-49]. This might be related to prolonged loss of appetite and loss of sleep. On the other hand, the high prevalence of underweight among the convicts could be due to low rations and quality of food served on top of severe prison related stress [50, 51]. Previous studies have also reported that prisoners faced a wide spectrum of nutritional problems [10-12, 14, 41, 52-54] and diets were not balanced [13, 54]. Nevertheless, it is important to note that our observed burden of underweight among the prisoners could be overestimated due to the fact that our study was based on prisoners who had respiratory/TB infection in which weight loss is a typical feature of such health problems.

One of the key determinants of underweight in the incarcerated population was chewing khat. Prisoners who chewed khat had a two-fold increased risk of becoming underweight. Sleep disturbance and loss of appetite associated with khat chewing could be the main explanations for the observed higher risk of underweight among khat chewing prisoners compared to their counterparts [55-58], 
Table 3 Factors associated with underweight among adult prisoners with respiratory infection in Tigray region in 2013/2014, northern Ethiopia $(n=787)$

\begin{tabular}{|c|c|c|c|c|c|}
\hline Variables & & Crude OR (95\% Cl) & $p$-value & Adjusted OR (95\% Cl) & $P$-value \\
\hline Age & 5 year increase & $0.91(0.86,0.98)$ & $0.007^{* *}$ & $0.95(0.87,1.03)$ & 0.207 \\
\hline \multirow[t]{2}{*}{ Family support } & No & 1.00 & & 1.00 & \\
\hline & Yes & $0.58(0.42,0.79)$ & $<0.001^{* * *}$ & $0.61(0.43,0.85)$ & $0.004^{* *}$ \\
\hline \multirow[t]{3}{*}{ Marital status } & Married & 1.00 & & 1.00 & \\
\hline & Single & $1.45(1.04,2.01)$ & $0.027^{*}$ & $0.87(0.58,1.31)$ & 0.499 \\
\hline & Divorced/widowed & $0.87(0.42,1.81)$ & 0.708 & $0.50(0.23,1.09)$ & 0.081 \\
\hline \multirow[t]{2}{*}{ Educational status } & No formal education & 1.00 & & & \\
\hline & Has formal education & $1.21(0.84,1.76)$ & 0.313 & $0.93(0.60,1.44)$ & 0.752 \\
\hline \multirow[t]{5}{*}{ Occupation } & Unemployed & 1.00 & & 1.00 & \\
\hline & Civil servant & $0.56(0.30,1.03)$ & 0.061 & $0.68(0.35,1.32)$ & 0.252 \\
\hline & Farmer & $0.51(0.33,0.8)$ & $0.003^{* *}$ & $0.59(0.36,0.98)$ & $0.042^{*}$ \\
\hline & Student & $1.13(0.65,1.95)$ & 0.674 & $1.16(0.65,2.08)$ & 0.614 \\
\hline & Other occupations & $0.72(0.40,1.30)$ & 0.270 & $0.83(0.45,1.54)$ & 0.552 \\
\hline Duration since jailed & 1 year increase & $1.04(0.99,1.10)$ & 0.131 & $1.07(1.01,1.14)$ & $0.026^{*}$ \\
\hline \multirow[t]{2}{*}{ Khat chewing } & No & 1.00 & & & \\
\hline & Yes & $2.68(1.65,4.35)$ & $<0.001^{* * *}$ & $2.08(1.17,3.70)$ & $0.013^{*}$ \\
\hline \multirow[t]{2}{*}{ Smoking } & No & 1.00 & & 1.00 & \\
\hline & Yes & $1.61(1.12,2.33)$ & $0.011^{*}$ & $0.92(0.58,1.46)$ & 0.727 \\
\hline \multirow[t]{2}{*}{ History of previous jail } & No & 1.00 & & 1.00 & \\
\hline & Yes & $1.84(1.21,2.81)$ & $0.005^{* *}$ & $1.54(0.99,2.42)$ & 0.058 \\
\hline \multirow[t]{2}{*}{ HIV } & Negative & 1.00 & & 1.00 & \\
\hline & Positive & $1.51(0.74,3.08)$ & 0.254 & $1.50(0.70,3.21)$ & 0.302 \\
\hline \multirow[t]{2}{*}{ Has TB } & No & 1.00 & & 1.00 & \\
\hline & Yes & $1.83(0.88,3.81)$ & 0.107 & $1.44(0.66,3.12)$ & 0.360 \\
\hline
\end{tabular}

${ }^{*}$ signifies for $p$-value $<0.05$, **signifies for $p$-value $<0.01$, and ${ }^{* * *}$ signifies $<0.001$

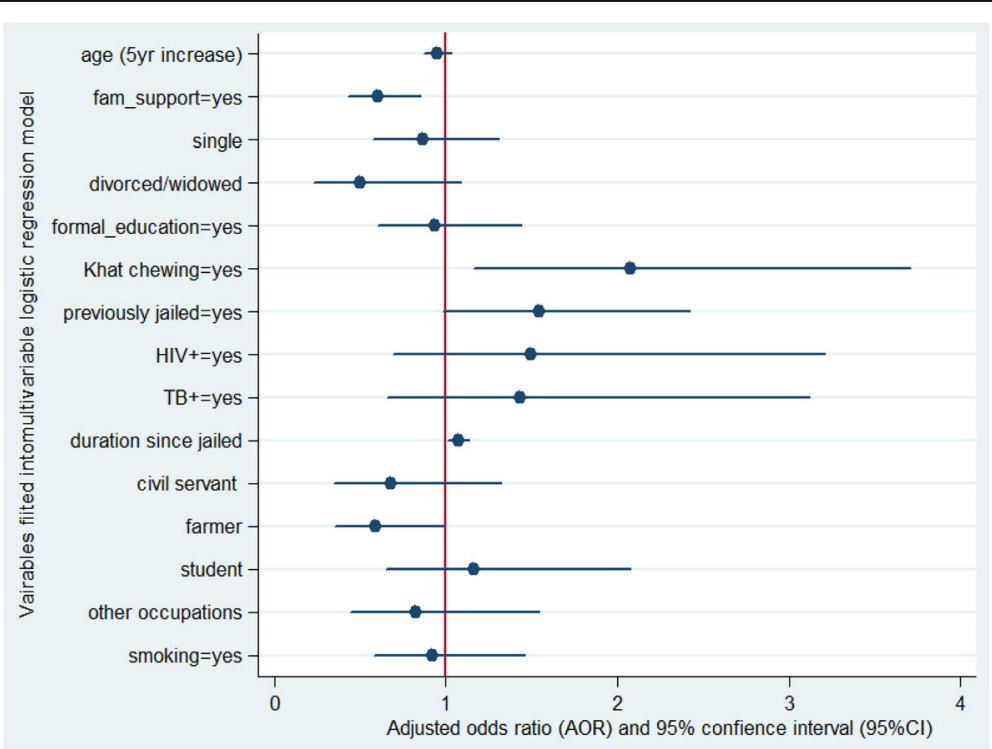

Fig. 2 Visual plots of the adjusted odds ratios, along with 95\% Cl, for each of fitted variable in to the multivariable binary logistic model 
rendering them susceptible to subsequent immunosuppression and repeated cycles of respiratory infections [35]. Such a deadly vicious cycle of interaction of undernutrition and infection, combined with possible deficiencies of several micronutrients, might further lead the prisoners to higher risk of severe morbidity and mortality.

Our study showed that there was a $41 \%$ lower risk of underweight for prisoners who were getting family support. Although we could not find literature linking family support and nutritional status of prisoners, it is a straight forward observation in that those who secured family support could be more likely to eat enough, achieve emotional and social support that could neutralize possible stress, and maintain a healthy life style such as personal hygiene. We assume that these health promoting conditions could finally lead them to lower risk of underweight compared to their counterparts.

Another important finding was that every one year additional imprisonment significantly translated to a $7 \%$ higher risk of underweight. This could imply that compared to prisoners who were imprisoned only for 1 year, those prisoners who were imprisoned for five years had approximately $35 \%$ higher risk of becoming underweight. Prior studies have also reported that longer duration of imprisonment was associated with significantly lower vitamin $\mathrm{D}$ level and lower values of serum proteins, mean corpuscular volume and haematocrit [12, 19, 54]. Within two years of incarceration, a 22 year old Nigerian detainee was found to develop severe underweight characterized by irreversible severe sensory and motor neuropathy of lower limbs and pulmonary TB [59]. Such severe underweight, also referred as "hunger disease", was also reported to be associated with death [51]. The higher risk of becoming underweight with longer duration of imprisonment could probably be due to harsh living conditions that might arise from long term exposure to psychological stress, overcrowding, possible humiliation, hunger, morbidity, poor personal hygiene and sanitation [51]. In a study done elsewhere, longer duration of incarceration was also associated with risk of drug use [60]. To further explain how longer duration of incarceration relates with underweight, in our analysis, we constructed a statistical scenario that examined if individuals with strong family support who were employed prior to their incarceration have better nutritional status early in their incarceration. If so, this might justify that food provided by prison institutions is of poor nutritional value over time. However, the analysis of the interaction of family support, duration of incarceration and employment status does not support the constructed scenario. Therefore, further research should be done to disentangle how longer duration of incarceration influences nutritional status of prisoners. Nevertheless, we strongly recommend that nutrition interventions in prison setups should be approached in an interdisciplinary and holistic perspective considering the duration of confinement and other public health factors, including overcrowding and poor environmental sanitation, to effectively address nutritional problems and promote overall health of prisoners. Moreover, prospective research should also aim to identify the critical time that prisoners become at risk of underweight and develop other nutritional disorders in order to widen the window of intervention opportunity.

Moreover, we have observed 54\% higher risk of underweight for prisoners who had history of previous incarceration with a borderline significance. Studies have shown that re-imprisonment was significantly determined by mental health, previous jail, younger age, drug and alcohol use [61-64]. Additionally, prisoners with previous history of incarceration had $40 \%$ more risk to have general medical problems [15] and poor clinical outcomes such as lower odds of HIV-1 suppression [65]. The findings of the abovementioned previous studies could also explain for the high burden of underweight observed in our study.

Unemployed prisoners were significantly associated with increased risk of underweight compared to farmers. Similarly, studies done in different settings have revealed that unemployment was associated with food insecurity, malnutrition and TB [66-69]. Poor economic access due to unemployment before incarceration could expose prisoners to risks of poor food quality, low food ration and other health related risk factors which may have led these prisoners to excess risk of underweight.

On the other hand, this study was able to demonstrate that TB, HIV sero-positivity and younger age were also associated with higher risk of underweight, but these associations were statistically insignificant. The absence of significant association between TB/HIV status and risk of underweight could be underestimated due to the small number of such clinical cases which might have neutralized the potentially pronounced reverse effects of these infections on the nutritional status of the prisoners.

This study has three important shortcomings which must be mentioned for cautious utilization of the results. First, this study was implemented among prisoners who had respiratory tract infections. Therefore, we assume that our findings may not be generalizable to all other prisoners in the sense that the level of underweight might have been overestimated due to the fact that weight loss is one of the typical features among individuals who are TB putative cases. Second, potential confounding variables of underweight such as mental health status were not adjusted in the multivariable analysis because it was the study's exclusion criteria due to the assumption that the data may not be reliable enough if the data would have come by interviewing such cases. A notable consequence of this is that our findings and conclusions could have been affected by a residual 
confounding although we did not quantify the level of this confounding. Third, despite the detailed training given to the data collectors as well as supervisors, strict implementation of our study procedures and measurements of the variables to enhance the validity and precision of our study, our attempt of quantifying the dose, frequency and duration of smoking and khat chewing was not precise enough. Due to this limitation, we were forced to perform our analyses simply based on the status of smoking and khat chewing. This might have limited our understanding of the potential effects of such unhealthy practices on the outcome variable.

This study, covering the whole major prison sites in the regional state and the first of its kind from Ethiopia, enquires into the extent of the problem of underweight, which is mostly an overlooked public health problem in the marginalized prison population particularly in developing countries. Hence, this study extends our knowledge about underweight and its associated factors in prisons in the context of Ethiopia which may have an enormous implication in initiating possible nutritional interventions in such a vulnerable population.

\section{Conclusion}

To conclude, the prevalence of underweight in the prison setups was high. Moderate and severe forms of underweight constitute more than one-third of the prevalent underweight cases. Absence of family support, khat chewing, longer duration of incarceration and unemployment were strong determinants of underweight. Previous history of incarceration and morbidities due to TB and HIV were also important factors worth considering, although the associations were statistically insignificant. We strongly recommend that political leaders, researchers and nongovernmental organizations (NGOs) come together to integrate holistic nutritional interventions to address underweight and reform the environmental health conditions to address underweight and promote overall health status of prisoners. Implementing therapeutic feeding programs for severely or moderately underweight prisoners should be one priority component of any nutritional interventions in prison settings.

\section{Abbreviations \\ BMI: Body mass index; Cl: Confidence interval; CM: Centimeter; FMoH: Federal Ministry of Health; GOF: Goodness of fit; HCT: HIV Counseling and Testing; HIV: Human Immunodeficiency Virus; ICPR: Institute for Criminal Policy Research; IQR: Inter Quartile Range; KG: Kilogram; NGOs: Non- governmental organizations; OR: Odds ratio; PTB: Pulmonary tuberculosis; TB: Tuberculosis; UDHR: Universal Declaration of Human Rights; VIF: Variance inflation factor; WHO: World Health Organization; WPB: World Prison Brief}

\section{Acknowledgement}

We are grateful to Mekelle University, through NORAD collaboration project, for funding the research project and we are also thankful to Commander Tsegay Uqubay, head of the regional prison health office, for facilitating the research process the study prison sites. We acknowledge AHRI for its support of reagents and laboratory facility to perform TB culture test. The funders have no role in the study design, collection, analysis and interpretation of the data. Last but not least, we are extremely grateful to our research participants, all staffs of the prison sites, staffs of the nearby health centers and clinical officers for all their tremendous support and time.

\section{Funding}

This study was funded by Mekelle University through NORAD collaboration project as part of TB in prison survey. Armauer Hansen Research Institute (AHRI) supported some reagents and provided laboratory setup to conduct TB culture test.

\section{Availability of data and materials}

Due to the sensitivity nature of the data, data is available with e-mail request to the corresponding author in addition to other materials such as questionnaire tool. Data can be requested e-mailing to semawfer@yahoo.com.

\section{Authors' contributions}

SFA and KA conceived, designed and performed experiments of the study. SFA analyzed the data, wrote the manuscript. SFA reviewed the manuscript. SFA had primary responsibility for the final content and led the response to review process. Both SFA and KA read and approved the final manuscript.

\section{Authors' information}

SFA is an Assistant Professor in the Department of Epidemiology and Biostatistics at the School of Public Health, College of Health Sciences, Mekelle University, Ethiopia. Currently, he is a PhD fellow at the Institute of Biological Chemistry and Nutrition in the University of Hohenheim, Stuttgart, Germany.

KA is a lecturer in the Department of Medical Microbiology and Immunology, College of Health Sciences, Mekelle University, Ethiopia. He is also a PhD fellow at Department of General Practice, CAPHRI School for Public Health and Primary Care in Maastricht University, The Netherlands.

\section{Competing interests}

The authors declare that they no competing interest.

Consent for publication

Not applicable.

\section{Ethics approval and consent to participate}

The study was approved by Ethical Review Committee of the College of Health Sciences in Mekelle University. The participants were enrolled after they agreed and provided us written informed consent. For illiterate participants, data collectors read the informed consent for each respondent and confirmed the willingness of the participants by signing on the informed consent sheet. Moreover, participants were instructed to stop participating in this study whenever they felt to do so.

Additionally, a letter of support was obtained from the Regional Prison Health Office in addition to direct call to heads of the nine prison institutions by the aforementioned responsible office.

\section{Publisher's Note}

Springer Nature remains neutral with regard to jurisdictional claims in published maps and institutional affiliations.

\section{Author details}

${ }^{1}$ School of Public Health, College of Health Sciences, Mekelle University, Mekelle, Ethiopia. ${ }^{2}$ Kilte Awlaelo- Health and Demographic Surveillance Site, Mekelle University, Tigray, Ethiopia. ${ }^{3}$ Department of Medical Microbiology and Immunology, College of Health Sciences, Mekelle University, Mekelle, Ethiopia.

Received: 31 January 2017 Accepted: 9 May 2017 Published online: 15 May 2017

\section{References}

1. Moeller L, Stöver H, Jürgens R, Gatherer A, Nikogosian H, World Health Organization, Regional Office for Europe. Health in prisons : a WHO guide to the essentials in prison health. WHO Regional Office for Europe: Copenhagen; 2007. 
2. Jeremy S. Prisons in Africa: an evaluation from a human rights perspective. Int J Hum Rights. 2008;4(9):22-49.

3. Herbert K, Plugge E, Foster C, Doll H. Prevalence of risk factors for noncommunicable diseases in prison populations worldwide: a systematic review. Lancet. 2012;379(9830):1975-82.

4. Minayo MC, Ribeiro AP. Health conditions of prisoners in the state of Rio de Janeiro, Brazil. Cien Saude Colet. 2016;21(7):2031-40.

5. Graham L, Fischbacher CM, Stockton D, Fraser A, Fleming M, Greig K. Understanding extreme mortality among prisoners: a national cohort study in Scotland using data linkage. Eur J Public Health. 2015;25(5):879-85.

6. Leach B, Goodwin S. Preventing malnutrition in prison. Nurs Stand. 2014 28(20):50-6. quiz 60

7. Winetsky DE, Almukhamedov O, Pulatov D, Vezhnina N, Dooronbekova A, Zhussupov B. Prevalence, risk factors and social context of active pulmonary tuberculosis among prison inmates in Tajikistan. PLoS One. 2014;9(1):e86046.

8. Rutta E, Mutasingwa D, Ngallaba S, Mwansasu A. Tuberculosis in a prison population in Mwanza, Tanzania (1994-1997). Int J Tuberc Lung Dis. 2001; 5(8):703-6.

9. Ake-Tano O, Konan EY, Tetchi EO, Ekou FK, Ekra D, Coulibaly A, Dagnan NS. Beriberi, recurrent nutritional disease in a detention house in cote-d'Ivoire. Bull Soc Pathol Exot. 2011;104(5):347-51.

10. Gould C, Tousignant B, Brian G, McKay R, Gibson R, Bailey K, Venn BJ. Crosssectional dietary deficiencies among a prison population in Papua New Guinea. BMC Int Health Hum Rights. 2013;13:21.

11. Brian G, Tousignant B, Venn BJ, McKay R, Gould C. Serum retinol and xerophthalmia among a prison population in Papua New Guinea. Ophthalmic Epidemiol. 2011;18(6):288-94.

12. Olubodun JO, Akinsola HA, Adeleye OA. Prison deprivation and protein nutritional status of inmates of a developing community prison. Eur J Clin Nutr. 1996;50(1):58-60.

13. Cook EA, Lee YM, White BD, Gropper SS. The diet of inmates: an analysis of a 28-day cycle menu used in a large county jail in the state of Georgia. J Correct Health Care. 2015;21(4):390-9.

14. Ahoua L, Etienne W, Fermon F, Godain G, Brown V, Kadjo K, Bouaffou K, Legros D, Guerin PJ. Outbreak of beriberi in a prison in cote d'Ivoire. Food Nutr Bull. 2007;28(3):283-90.

15. Cuddeback GS, Scheyett A, Pettus-Davis C, Morrissey JP. General medical problems of incarcerated persons with severe and persistent mental illness: a population-based study. Psychiatr Serv. 2010;61(1):45-9.

16. Fialho M, Messias M, Page-Shafer K, Farre L, Schmalb M, Pedral-Sampaio D, Ramos M, Brites C. Prevalence and risk of blood-borne and sexually transmitted viral infections in incarcerated youth in Salvador, Brazil: opportunity and obligation for intervention. AIDS Behav. 2008;12(4 Suppl):S17-24.

17. Murray N, LePage E, Butler T. Hearing health of new South Wales prison inmates. Aust N Z J Public Health. 2004;28(6):537-41.

18. Jarrett $M$, Valmaggia $L$, Parrott J, Forrester A, Winton-Brown T, Maguire $H$, Ndegwa D, McGuire P, Craig TK. Prisoners at ultra-high-risk for psychosis: a cross-sectional study. Epidemiol Psychiatr Sci. 2016;25(2):150-9.

19. Jacobs ET, Mullany CJ. Vitamin D deficiency and inadequacy in a correctional population. Nutrition. 2015;31(5):659-63.

20. Butler T, Malacova E, Richters J, Yap L, Grant L, Richards A, Smith AM, Donovan B. Sexual behaviour and sexual health of Australian prisoners. Sex Health. 2013;10(1):64-73.

21. Fox GJ, Lee RS, Lucas M, Khan FA, Proulx JF, Hornby K, Jung S, Benedetti A, Behr MA, Menzies D. Inadequate diet is associated with acquiring mycobacterium tuberculosis infection in an Inuit community. A case-control study. Ann Am Thorac Soc. 2015;12(8):1153-62.

22. Akuzawa $\mathrm{N}$, Naito $\mathrm{H}$. Nutritional parameters affecting severity of pneumonia and length of hospital stay in patients with pneumococcal pneumonia: a retrospective cross-sectional study. BMC Pulm Med. 2015;15:149.

23. Zhao G, Ford ES, Tsai J, Li C, Croft JB. Low concentrations of serum 25hydroxyvitamin D associated with increased risk for chronic bronchitis among US adults. Br J Nutr. 2012;107(9):1386-92.

24. Monlezun DJ, Bittner EA, Christopher KB, Camargo CA, Quraishi SA. Vitamin $D$ status and acute respiratory infection: cross sectional results from the United States National Health and nutrition examination survey, 2001-2006. Nutrients. 2015;7(3):1933-44.

25. Barnett JB, Hamer DH, Meydani SN. Low zinc status: a new risk factor for pneumonia in the elderly? Nutr Rev. 2010;68(1):30-7.

26. World Prison Brief, Institute for Criminal Policy Research: World Prison Population List. In.; 2015.
27. United Nations: United Nations universal Declaration of human rights; 1948.

28. United Nations: Resolution adopted by the General Assembly on 17 December 2015: United Nations Standard Minimum Rules for the Treatment of Prisoners (the Nelson Mandela Rules) In: A/70/490. Edited by United Nations; 2015

29. Adane K, Spigt M, Ferede S, Asmelash T, Abebe M, Dinant GJ. Half of pulmonary tuberculosis cases were left undiagnosed in prisons of the Tigray region of Ethiopia: implications for tuberculosis control. PLoS One. 2016; 11(2):e0149453.

30. World Health Organization. Physical status: the use of and interpretation of anthropometry. In: WTR S, editor. Report of a WHO expert committee. Geneva: World Health Organization; 1995.

31. World Health Organization: Obesity: Preventing and managing the global epidemic 2000. In: Report of a WHO Consultation: WHO Technical Report Series 894. Geneva: World Health Organization; 2000.

32. Hosmer D, Lemeshow S: Applied survival analysis regression modeling of time to event data: a Wiley-Interscience publication; 1999.

33. O'Brien RM. A caution regarding Rules of thumb for variance inflation factors. Quality \& Quantity. 2007:41(5):673.

34. Rochester DF, Esau SA. Malnutrition and the respiratory system. Chest. 1984:85:411-5.

35. Schaible UE, Kaufmann SH. Malnutrition and infection: complex mechanisms and global impacts. PLoS Med. 2007:4(5):e115.

36. He CS, Handzlik M, Fraser WD, Muhamad A, Preston H, Richardson A, Gleeson M. Influence of vitamin D status on respiratory infection incidence and immune function during 4 months of winter training in endurance sport athletes. Exerc Immunol Rev. 2013;19:86-101.

37. Laaksi I. Vitamin D and respiratory infection in adults. Proc Nutr Soc. 2012;71(1):90-7.

38. Miyata S, Tanaka M, Ihaku D. The prognostic significance of nutritional status using malnutrition universal screening tool in patients with pulmonary tuberculosis. Nutr J. 2013;12:42.

39. De Maayer $\mathrm{T}$, Saloojee $\mathrm{H}$. Clinical outcomes of severe malnutrition in a high tuberculosis and HIV setting. Arch Dis Child. 2011;96(6):560-4.

40. Cisse FA, Konate MM, Ekue WA, Cisse M, Camara N, Djigue BS, Balde AO, Camara IA, Diallo FL, Diallo BS, et al. Clinical appearance and scalable profile thiamine deficiency in prison in Guinea: study of thirty-eight observations. Bull Soc Pathol Exot. 2016;109(2):70-6.

41. Mathenge W, Kuper H, Myatt M, Foster A, Gilbert C. Vitamin a deficiency in a Kenyan prison. Trop Med Int Health. 2007;12(2):269-73.

42. Ehteshamfar SM, Shapouri-Moghaddam A, Safarian M, Nematy M, BahramiTaghanaki H, Azizi H. Serum selenium concentration in Mashhad prisoners, Iran. Saudi Med J. 2012;33(8):859-62.

43. Bennett $M$, Coninx R. The mystery of the wooden leg: vitamin C deficiency in east African prisons. Trop Doct. 2005:35(2):81-4.

44. Lee BY, Thurmon TF. Nutritional disorders in a concentration camp. J Am Coll Nutr. 1997;16(4):366-75.

45. Zimbabwe: addressing the essential needs of prisoners. Available on https://www.icrc.org/eng/assets/files/annual-report/current/icrc-annualreport-harare.pdf. Accessed 12 Jan 2017.

46. Mack KJ, Collins M. Access to oral health care in the Georgia prison system. J Dent Hyg. 2013;87(5):271-4.

47. Kinner SA, Streitberg L, Butler T, Levy M. Prisoner and ex-prisoner health improving access to primary care. Aust Fam Physician. 2012;41(7):535-7.

48. Kulkarni SP, Baldwin S, Lightstone AS, Gelberg L, Diamant AL. Is incarceration a contributor to health disparities? Access to care of formerly incarcerated adults. J Community Health. 2010;35(3):268-74.

49. Restum ZG. Public health implications of substandard correctional health care. Am J Public Health. 2005;95(10):1689-91.

50. Tharakan T. Nutrition in warfare: a retrospective evaluation of undernourishment in RAF prisoners of war during World war II. Med Humanit. 2010;36(1):52-6.

51. Shasha SM. Morbidity in the concentration camps of the third Reich. Harefuah. 2004:143(4):272-6. 318

52. Tousignant B, Brian G, Venn BJ, Gould C, McKay R, Williams S. Optic neuropathy among a prison population in Papua New Guinea. Ophthalmic Epidemiol. 2013;20(1):4-12

53. de Montmollin D, MacPhail J, McMahon J, Coninx R. Outbreak of beri-beri in a prison in West Africa. Trop Doct. 2002;32(4):234-6.

54. Pavlovic M, Zavalic M, Corovic N, Stilinovic L, Malinar M. Loss of body mass in ex-prisoners of war. Eur J Clin Nutr. 1993;47(11):808-14. 
55. Teni FS, Surur AS, Hailemariam A, Aye A, Mitiku G, Gurmu AE, Tessema B. Prevalence, reasons, and perceived effects of Khat chewing among students of a College in Gondar Town, northwestern Ethiopia: a cross-sectional study. Ann Med Health Sci Res. 2015;5(6):454-60.

56. Lemieux AM, Li B, al' Absi M. Khat use and appetite: an overview and comparison of amphetamine, khat and cathinone. J Ethnopharmacol. 2015;160:78-85.

57. Pennings EJ, Opperhuizen A, van Amsterdam JG. Risk assessment of khat use in the Netherlands: a review based on adverse health effects, prevalence, criminal involvement and public order. Regul Toxicol Pharmacol. 2008;52(3):199-207.

58. Ageely HM. Health and socio-economic hazards associated with khat consumption. J Family Community Med. 2008;15(1):3-11.

59. Olubodun JO, Jayesimi AE, Olasode OA, Sobowale AB. Severe clinical nutritional neurological damage in a young Nigerian detainee. Trop Geogr Med. 1991;43(1-2):231-3.

60. Rowell TL, Wu E, Hart CL, Haile R, El-Bassel N. Predictors of drug use in prison among incarcerated black men. Am J Drug Alcohol Abuse. 2012;38(6):593-7.

61. Hartwell S, Fisher W, Deng X, Pinals DA, Siegfriedt J. Intensity of offending following state prison release among persons treated for mental health problems while incarcerated. Psychiatr Serv. 2016;67(1):49-54

62. Haines A, Lane S, McGuire J, Perkins E, Whittington R. Offending outcomes of a mental health youth diversion pilot scheme in England. Crim Behav Ment Health. 2015;25(2):126-40.

63. Ayirolimeethal A, Ragesh G, Ramanujam JM, George B. Psychiatric morbidity among prisoners. Indian J Psychiatry. 2014;56(2):150-3.

64. Maden A, Skapinakis P, Lewis G, Scott F, Jamieson E. Gender differences in reoffending after discharge from medium-secure units. National cohort study in England and Wales. Br J Psychiatry. 2006;189:168-72.

65. Palepu A, Tyndall MW, Li K, Yip B, O'Shaughnessy MV, Schechter MT, Montaner JS, Hogg RS. Alcohol use and incarceration adversely affect HIV-1 RNA suppression among injection drug users starting antiretroviral therapy. J Urban Health. 2003;80(4):667-75.

66. Abdollahi M, Abdollahi Z, Sheikholeslam R, Kalantari N, Kavehi Z, Neyestani TR High occurrence of food insecurity among urban afghan refugees in Pakdasht, Iran 2008: a cross-sectional study. Ecol Food Nutr. 2015:54(3):187-99.

67. Blachnio M, Zielonka TM, Blachnio A, Jagodzinski J. Socio-economic status and the duration of pulmonary tuberculosis symptoms in women treated at the Mazovian treatment Centre of Tuberculosis and Lung Diseases in Otwock. Pneumonol Alergol Pol. 2014;82(1):3-9.

68. Hailemariam S, Bune GT, Ayele HT. Malnutrition: prevalence and its associated factors in people living with HIV/AIDS, in Dilla University referral hospital. Arch Public Health. 2013;71(1):13.

69. Matulessy PF, Asumi R, Thamrin MH, Husaini, Angeles TI, Kariadi D. Nutrition situation in metropolitan Jakarta. Southeast Asian J Trop Med Public Health. 1992;23(Suppl 3):3-16.

\section{Submit your next manuscript to BioMed Central and we will help you at every step:}

- We accept pre-submission inquiries

- Our selector tool helps you to find the most relevant journal

- We provide round the clock customer support

- Convenient online submission

- Thorough peer review

- Inclusion in PubMed and all major indexing services

- Maximum visibility for your research

Submit your manuscript at www.biomedcentral.com/submit 